\title{
Overdose of carbamazepine before hanging by a child: a case report of a complex suicide
}

\author{
Amal Nishantha Vadysinghe ${ }^{*}$ and Solokara Mudiyanselage Nirmani Kaushalya Thilakarathne
}

\begin{abstract}
Background: Compared to death by hanging, fatal cases due to carbamazapine intake is hardly seen. We are reporting a rare case where the victim had used this combination to terminate life as a complex suicide.

Case presentation: The deceased was a 16-year-old school girl, who had been on carbamazepine for 10 years for epilepsy. Following a heated argument with her family members, who had disapproved of her love affair, the victim was found hanging from a rafter in her bedroom, with a plume of froth coming from both nostrils and mouth. A complete death investigation, including scene investigation and complete autopsy examination, was carried out. Her stomach contained pieces of tablets which were later confirmed to be carbamazepine, which was also seen in fatal levels in the blood. The cause of death was confirmed as hanging, in a patient who had ingested a massive dose of carbamazepine. The manner of death was suicide and more towards planned complex type.

Conclusion: The value of toxicological analysis should not be underestimated even in cases of hanging. This case further highlights the responsibility cast upon the guardians of children diagnosed with chronic diseases like epilepsy, where stressful situations need to be handled in a tactful manner, to avoid catastrophic consequences.
\end{abstract}

Keywords: Carbamazepine, Complex suicide, Epilepsy, Partial hanging

\section{Background}

Suicide is a major public health issue and one of the leading causes of death among the non-communicable disease category (WHO Regional Office for South-East Asia 2001), and it is one of the commonest unnatural causes of death in teenagers. Adolescents are more vulnerable to suicidal attempts than any other time in their life (Miranda and Shaffer 2013; Bridge et al. 2006)

Hanging is the commonest method in suicides (Ajdacic-Gross et al. 2008), where the neck is compressed by a ligature and the force is derived from the weight of the body (Saukko and Knight 2016; Dolinak and Matshes 2005).

Carbamazepine (CBZ) is a widely used drug as an anticonvulsant to control seizure, and the intoxication is readily seen due to being freely available in the community (Graudins et al. 2002; Sweetman 2009). The first

\footnotetext{
* Correspondence: amal_vadysinghe@yahoo.com

Department of Forensic Medicine, Faculty of Medicine, University of Peradeniya, Peradeniya, Sri Lanka
}

few cases of deaths due to CBZ were documented by Baselt (1982) and Denning et al. (1985) in the early 1980s (Baselt 1982; Denning et al. 1985), and intoxication is not uncommon in emergency medical setup.

In cases of complex suicides, two or more methods are used to terminate life simultaneously or one after another (Toro and Pollak 2009; Cascini et al. 2012; Cingolani and Tsakri 2000). We present a case of hanging of a teenage female who has ingested a large dose of CBZ which was given to her for epilepsy and such a case has not been reported previously.

\section{Case presentation}

A deceased body of a 16-year-old school girl was brought by the police as directed by the magistrate, to the unit of forensic pathology, at a Teaching Hospital in Peradeniya, Peradeniya Sri Lanka.

The deceased was found hanging by a nylon cloth (saree) from a rafter of her room. The clothes were not disturbed. Both legs were partially flexed at the knees and touching the ground. It appeared that the deceased used her study 
table to reach the rafter to tie one end of the nylon cloth and the other side was used to tie her neck.

There was a letter describing the suicide as a consequence of repeated objections from her parents, for her love affair. There were a few tablets of carbamazepine (CBZ) found on her bed, possibly from the drug bag, which had been given at a routine clinic follow-up for her epilepsy.

The victim was the youngest of the family, was studying in a high school, and had two brothers who were engaged in higher studies. Her father was a timber trader. The victim had a love affair with a person who was elder to her by 10 years, which had continued for 2 years prior, with repeated objections from her family. She was strongly advised to stop this affair by school teachers, relatives, and even from family members of the partner. Furthermore, she had been diagnosed with epilepsy and was on CBZ since 5 years of age. She was following her routine epileptic clinic appointments on a regular basis with her parents, she had been tolerating CBZ well, and her routine blood investigations including blood counts were within normal range.

On this particular day, there was a heated argument between the brothers and the victim, due to her poor school performance and it surfaced that her love affair may have been responsible for it. She went inside her room and locked it without having lunch. Similar instances were not unfamiliar during the last 2 years for similar reasons. But this time, there was no response from her after repeated knocking on the door by her mother. Finally, they had broken the door and found the victim hanging by a nylon cloth. They had taken the victim to the nearest hospital because the body was still warm, after cutting the ligature close to the raft and loosening the noose around her neck. The victim was pronounced dead on admission. Due to the plume of froth coming from the nostrils (Fig. 1), which was an unusual feature of hanging, the deceased was transferred to the forensic unit for an autopsy. There were no past attempts of suicide, and she had not been complaining about her medications and had been attending clinic appointments.
The autopsy was conducted on request of the inquirer into sudden death, approximately $18 \mathrm{~h}$ after confirming the death. The body was well preserved in a refrigerator, at the morgue at the Department of Forensic Medicine, University of Peradeniya, Sri Lanka. The autopsy revealed a 54- $\mathrm{kg}$ Asian Caucasoid of $158 \mathrm{~cm}$ in height. There was no evidence of physical or congenital deformities or putrefaction. The deceased was clad in a short sleeved ash-white jacket, blue-colored skirt, and white-colored brazier and underwear. There were no tears on the clothes. Her hands and legs were free of injuries and stains. Plume of whitish froth (Fig. 1) was seen in the nostrils and respiratory passage up to secondary division of the bronchioles. Both lungs were heavy (left, $665 \mathrm{~g}$ and right, $710 \mathrm{~g}$ ), and severe pulmonary edema was also confirmed microscopically (Fig. 2). Both the eyes and face were pale, and no petechial hemorrhages were observed in the sclera or conjunctivae (Fig. 3).

Friction abrasions of $2 \mathrm{~cm}$ in width were seen around the neck, above the thyroid cartilage anteriorly, and running upwards towards back of the neck, where the knot of the nylon cloth had been placed (Fig. 4a). It was deeply grooved on the anterior side of the neck, with the impressions seen minimally under the knot on the back (Fig. 4b). A single circle of the nylon cloth had been applied around the neck, but the knot had slid and was placed on the posterior aspect of the neck, towards the right.

There were no other soft tissue, cervical spine, laryngeal, or skeletal injuries on the neck. There was no congestion, submucosal injuries, hemorrhages, or erosion on the nasal oral cavity, esophagus, or stomach. There were identifiable pieces of tablets seen in the stomach, and these were mixed with the gastric secretion and were later identified as CBZ.

No other traumatic lesions or defensive wounds were seen on the body. No natural disease conditions were diagnosed macroscopically or microscopically. Furthermore, there were no evidence of chronic toxicity caused by CBZ clinically and at autopsy including hepatitis and pancreatitis (Keränen and Sivenius 1983).

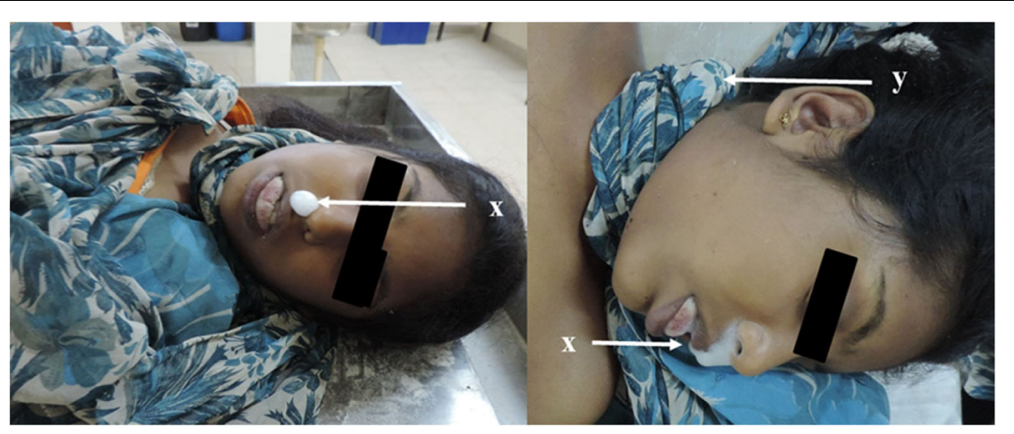

Fig. 1 Plume of froth (indicated by arrow $x$ ) coming from the nostrils and the mouth, the nylon cloth (indicated by arrow $y$ ) used in hanging 


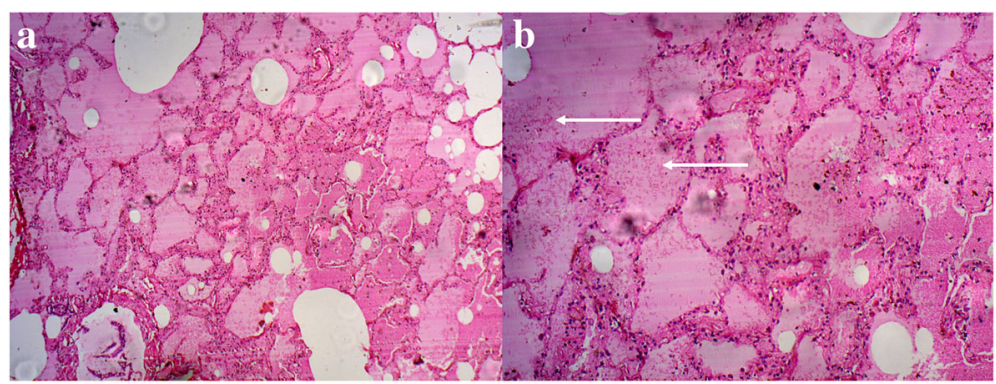

Fig. 2 Photomicrograph of lung, hematoxylin and eosin (H\&E) stain ( $a: \times 5 ; b: \times 10)$; alveolar spaces are filled with edema fluid (pink homogenous proteinaceous material) indicated by an arrow

Blood samples from the femoral vein were prepared by using alkaline extraction method (chloroform). Then, the samples were tested for CBZ using gas chromatographymass spectrometry method. The toxicology report revealed a blood CBZ level of $30 \mathrm{mg} / \mathrm{L}$ which is close to the fatal amount $(40 \mathrm{mg} / \mathrm{L}$ ) (Yaylaci et al. 2012).There were no other toxic substances, including common therapeutic or illicit drugs in the stomach contents, liver, kidney, or blood.

Further analysis of her height, the height of the rafter, and the length of the two knots of the cloth is compatible with partial suspension.

Subsequent to medicolegal death investigation, including full autopsy examination, the cause of death was concluded as hanging of a person ingested with CBZ and the manner of death was suicide.

\section{Discussion}

The term asphyxia includes a variety of conditions that result in interference with the uptake/utilization or lack of oxygen. The most vulnerable organ to hypoxia is the brain (WHO Regional Office for South-East Asia 2001; Sweetman 2009). Suicide attempts are common during adolescence and are more common among females

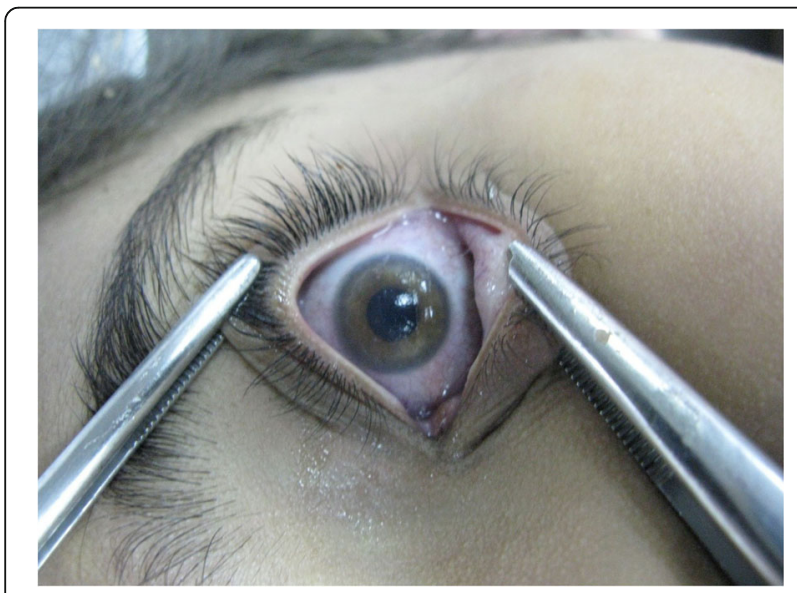

Fig. 3 The left eye with conjunctiva. No congestion or hemorrhages in sub-sclera/conjunctiva
(Miranda and Shaffer 2013; Bridge et al. 2006; Eaton et al. 2012). Hanging is one of the commonest methods of suicide among adolescents (Beautrais 2000; Bridge et al. 2005).

Many studies revealed that there is a higher risk of committing suicide among those who have a diagnosis of epilepsy, in comparison to those who do not (Cockerell et al. 1994; Rafnsson et al. 2001, Pompili et al. 2005, Pompili et al. 2006), and some studies showed higher rates of depression among those who have chronic diseases like epilepsy (Brent and Birmaher 2002, Suris et al. 1996). A greater proportion of females with chronic illnesses like epilepsy report feeling sad, have suicidal thoughts, and have other symptoms of depression (Verrotti et al. 2008). These symptoms may have been present in our case, despite not being noticed by others.

Furthermore, the incident took place after a stressful situation, which may have facilitated (Dieserud et al. 2010; Simon et al. 2001) her to commit suicide, by either overdose of CBZ or hanging.

Drug overdose is a recognized method of attempting suicide among adolescents (Dieserud et al. 2010; Hawton 1982; Michel et al. 2000), and this victim used her therapeutic drugs which were under her custody, to terminate her life with hanging.

In this case, the victim used cloth/saree as ligature material, which is consistent with previous studies (Bhosle et al. 2015; Singh et al. 2013). In females, the preferred site for hanging is indoors or bed rooms and this victim used her bed room (Singh et al. 2013, Shaw et al. 2005).

In this case, the autopsy, measurements of the body including the ligature and scene findings pointed towards the partial suspension/hanging which is common in suicides (Saukko and Knight 2016; Callanan and Davis 2012; Payne-James et al. 2011; DiMaio and DiMaio 2001; Dean et al. 2012).

There were no injuries other than the ligature mark around the neck or face, which again excluded the forceful ingestion of the drugs or homicidal hanging, which is an extremely rare occurrence (Plueckhahn 1968; Feldeman and Simms 1980). 


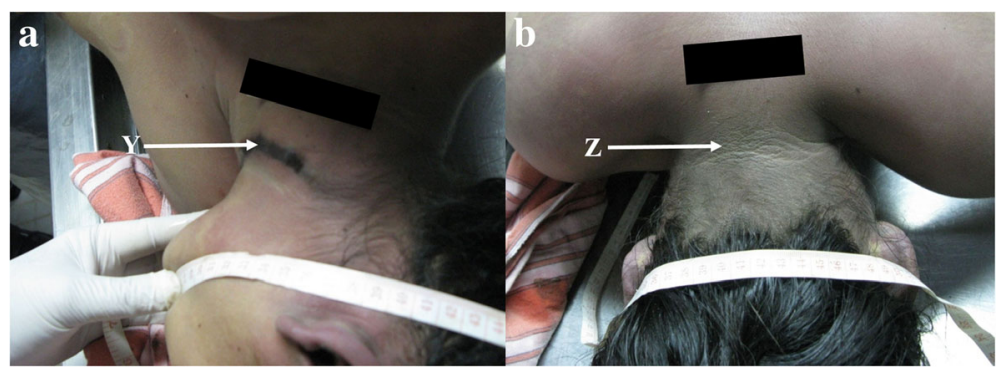

Fig. 4 a Right side of the neck with friction abrasions running upwards towards back of the neck, and it was deeply grooved on the anterior side (indicated by arrow $Y$ ) with the impressions seen minimally towards back (indicated by arrow Z). There were no edema, congestion, or petechial hemorrhage above the constriction mark. b Back aspect, ligature mark impressions seen minimally under the knot

Complex suicide describes the use of more than one method to cause death. These methods may be induced simultaneously or sequentially (Bohnert 2005), and approximately, $1-5 \%$ is responsible for all suicides (Hofmann and Herber 1984; Racette and Sauvageau 2007; Bohnert 2005; Demirci et al. 2009).

In this case, CBZ, an epileptic drug identified in the blood, is well above the therapeutic amount and close to the fatal level. There are few studies mentioning CBZ poisoning due to overdose (Kinoshita et al. 2010). CBZ is known to affect the cardiac conduction system and cause respiratory failure and arrest and central nervous system depression (Schmidt and Schmitz-Buhl 1995).

According to blood CBZ levels, poisoning can be classified into four stages: potentially catastrophic relapse with levels $<11 \mathrm{mg} / \mathrm{L}$, disorientation and ataxia at levels of $11-15 \mathrm{mg} / \mathrm{L}$, combativeness and hallucinations at levels of $15-25 \mathrm{mg} / \mathrm{L}$, and convulsions and coma at levels $>25 \mathrm{mg} / \mathrm{L}$ (Yaylaci et al. 2012).

It is likely that the victim had planned the act of hanging prior to or just following ingestion of the drug. However, it may be considered that the fatal act had occurred when reaching towards the lethal level possibly during stage 4 of $\mathrm{CBZ}$ poisoning.

Again pulmonary edema may also be seen in a massive overdose of CBZ (Kitson and Wauchob 1988) and possibly more than $25 \mathrm{mg} / \mathrm{L}$, and it can produce froth similar to the presented case.

Froth is an edema fluid of the lung (Saukko and Knight 2016), and it is seen in many causes of mechanical obstruction, such as an interrupted hanging, strangulation, and drowning (Timby et al. 1990; Bohnert et al. 2002). Negative pressure pulmonary edema (NPPE) is an entity which is caused by upper air way obstruction which is potentially fatal (Bhaskar and Fraser 2011). The massive effort of breathing against obstruction leads the fluid to move out of the pulmonary capillaries and into the interstitial and alveolar spaces (Butterell and Riley 2002; Willms and Shure 1988). Another mechanism of pulmonary edema is based on Starling equation and is especially seen in cardiac failure like in our case (Ware and Matthay 2005; Murray 2011).

In this case, the absence of asphyxial features, on the face and above the ligature, or even the tissue reaction around the constriction mark, favors a rapid death possibly due to mechanism of instantaneous neurogenic cardiac arrest (INCA) or reflex-triggered cardiac arrest (Purdue 2000). Therefore, the froth noticed on this victim is due to acute CBZ over dose than hanging.

Therefore, this case points towards a planned type complex suicide than unplanned (Bohnert 2005).

\section{Conclusion}

This is a case of a planned complex suicide by ingestion of massive dose of CBZ followed by hanging. This case further emphasizes the need for careful handling of children who have chronic diseases, like epilepsy, especially in stressful situations, to avoid fatal consequences.

\section{Abbreviation}

CBZ: Carbamazepine

\section{Acknowledgments}

Not applicable.

Funding

None.

Availability of data and materials

All data and materials used during this study are included in this article.

\section{Authors' contributions}

ANV performed and was involved in the medico legal autopsy, concept, design, data interpretation, figures, and manuscript writing of the study. SMNKT was involved in the manuscript writing, formatting, and figures. Both authors read and approved the final manuscript.

Ethics approval and consent to participate

All procedures performed in the study were in accordance with the ethical standards of the institution and with the 1964 Helsinki Declaration and its later amendments or comparable ethical standards. Informed consent was obtained from the relatives.

Consent for publication

Not applicable. 


\section{Competing interests}

The authors declare that they have no competing interests.

\section{Publisher's Note}

Springer Nature remains neutral with regard to jurisdictional claims in published maps and institutional affiliations.

Received: 5 July 2018 Accepted: 6 November 2018

Published online: 19 November 2018

\section{References}

Ajdacic-Gross V, Weiss MG, Ring M, Hepp U, Bopp M, Gutzwiller F, Rössler W (2008) Methods of suicide: international suicide patterns derived from the WHO mortality database. Bull World Health Organ 86:726-732

Baselt RC (ed) (1982) Disposition of toxic drugs and chemicals in man, 2nd edn. Biomedical Publications, California

Beautrais AL (2000) Methods of youth suicide in New Zealand: trends and implications for prevention. Aust N Z J Psychiatry 34(3):413-419

Bhaskar B, Fraser JF (2011) Negative pressure pulmonary edema revisited: pathophysiology and review of management. Saudi J Anaesth 5(3):308

Bhosle SH, Zanjad NP, Dake MD, Godbole HV (2015) Deaths due to hanging among adolescents-a 10-year retrospective study. J Forensic Legal Med 29 30-33

Bohnert M (2005) Complex suicides. In: Tsokos M (ed) Forensic pathology reviews. Humana Press Inc, New Jersey

Bohnert M, Ropohl D, Pollak S (2002) Forensic medicine significance of the fluid content of the sphenoid sinuses. Archiv fur Kriminologie 209(5-6):158-164

Brent DA, Birmaher B (2002) Adolescent depression. N Engl J Med 347(9):667-671

Bridge JA, Barbe RP, Brent DA (2005) Datapoints: recent trends in suicide among US adolescent males, 1992-2001. Psychiatr Serv 56(5):522

Bridge JA, Goldstein TR, Brent DA (2006) Adolescent suicide and suicidal behavior. J Child Psychol Psychiatr 47(3-4):372-394

Butterell H, Riley RH (2002) Life-threatening pulmonary oedema secondary to tracheal compression. Anaesth Intensive Care 30(6):804

Callanan VJ, Davis MS (2012) Gender differences in suicide methods. Soc Psychiatry Psychiatr Epidemiol 47(6):857-869

Cascini F, Longo F, Polacco M, Scafetta I (2012) Foreign object ingestion in complex suicide: a case report and review of the literature. Forensic Sci Int 219(1-3):e1-e3

Cingolani M, Tsakri D (2000) Planned complex suicide: report of three cases. Am J Forensic Med Pathol 21(3):255-260

Cockerell OC, Hart YM, Sander JW, Goodridge DM, Shorvon SD, Johnson AL (1994) Mortality from epilepsy: results from a prospective population-based study. Lancet 344(8927):918-921

Dean DE, Kohler L, Sterbenz GC, Gillespie PJ, Gonzaga NS, Bauer LJ, Looman K, Owens OD (2012) Observed characteristics of suicidal hangings: an 11-year retrospective review. J Forensic Sci 57(5):1226-1230

Demirci S, Dogan KH, Erkol Z, Deniz I (2009) A series of complex suicide. Am J Forensic Med Pathol 30(2):152-154

Denning DW, Matheson L, Bryson SM, Streete J, Berry DJ, Henry JA (1985) Death due to carbamazepine self-poisoning: remedies reviewed. Hum Exp Toxicol 4(3):255-260

Dieserud G, Gerhardsen RM, Van den Weghe H, Corbett K (2010) Adolescent suicide attempts in Baerum, Norway, 1984-2006. Crisis 31(5):255-264

DiMaio VJ, DiMaio D (eds) (2001) Forensic pathology, 2nd edn. CRC Press, New York

Dolinak D, Matshes E (2005) Asphyxia. In: Dolinak D, Matshes EW, Lew EO (eds) Forensic pathology, principles and practice. Elsevier Academic Press, San Diego

Eaton DK, Kann L, Kinchen S, Shanklin S, Flint KH, Hawkins J, Harris WA, Lowry R, McManus T, Chyen D, Whittle L (2012) Youth risk behavior surveillance-United States, 2011. Morb Mortal Wkly Rep Surveill Summ. 61(4):1-62

Feldeman KW, Simms RJ (1980) Strangulation in childhood: epidemiology and clinical course. Pediatrics 65(6):1079-1085

Graudins A, Peden G, Dowsett RP (2002) Massive overdose with controlledrelease carbamazepine resulting in delayed peak serum concentrations and life-threatening toxicity. Emerg Med Australas 14(1):89-94

Hawton K (1982) Attempted suicide in children and adolescents. J Child Psycho Psychiatry 23(4):497-503
Hofmann V, Herber F (1984) Überkombinierte und protrahierte Suizide. Kriminalforens Wiss 53(54):83-88

Keränen T, Sivenius J (1983) Side effects of carbamazepine, valproate and clonazepam during long-term treatment of epilepsy. Acta Neurol Scand 68 . $69-80$

Kinoshita H, Morikawa K, Kuze A, Nagasaki Y, Takahashi M, Nishiguchi M, Nishio H, Ueno Y, Jamal M, Kubo Y, Tanaka N (2010) An autopsy case of carbamazepine poisoning. Soudnilekarstvi 55(2):22-24

Kitson GE, Wauchob TD (1988) Pulmonary oedema following carbamazepine overdose. Anaesthesia 43(11):967-969

Michel K, Ballinari P, Bille-Brahe U, Bjerke T, Crepet P, De Leo D, Haring C, Hawton K, Kerkhof A, Lönnqvist J, Querejeta I (2000) Methods used for parasuicide: results of the WHO/EURO multicentre study on parasuicide. Soc Psychiatry Psychiatr Epidemiol 35(4):156-163

Miranda R, Shaffer D (2013) Understanding the suicidal moment in adolescence. Ann N Y Acad Sci 1304(1):14-21

Murray JF (2011) Pulmonary edema: pathophysiology and diagnosis. Int J Tuberc Lung Dis 15(2):155-160

Payne-James J, Jones R, Karch SB, Manlove J (2011) Simpson's forensic medicine. Hodder Arnold, London

Plueckhahn VD (1968) The evaluation of autopsy blood alcohol levels. Med Sci Law 8(3):168-176

Pompili M, Girardi P, Ruberto A, Tatarelli R (2005) Suicide in the epilepsies: a meta-analytic investigation of 29 cohorts. Epilepsy Behav 7(2):305-310

Pompili M, Girardi P, Tatarelli R (2006) Death from suicide versus mortality from epilepsy in the epilepsies: a meta-analysis. Epilepsy Behav 9(4):641-648

Purdue BN (2000) Asphyxial and related deaths. In: Mason JK, Purdue BN (eds) The pathology of trauma, 3rd edn. Arnold, London

Racette S, Sauvageau A (2007) Planned and unplanned complex suicides: a 5year retrospective study. J Forensic Sci 52(2):449-452

Rafnsson V, Ólafsson E, Hauser WA, Gudmundsson G (2001) Cause-specific mortality in adults with unprovoked seizures. Neuroepidemiology 20(4):232-236

Saukko P, Knight B (eds) (2016) Knight's forensic pathology, 4th edn. CRC Press, New York

Schmidt S, Schmitz-Buhl M (1995) Signs and symptoms of carbamazepine overdose. J Neurol 242(3):169-173

Shaw D, Fernandes JR, Rao C (2005) Suicide in children and adolescents: a 10year retrospective review. Am J Forensic Med Pathol 26(4):309-315

Simon TR, Swann AC, Powell KE, Potter LB, Kresnow MJ, O'Carroll PW (2001) Characteristics of impulsive suicide attempts and attempters. Suicide Life Threat Behav 32(Supplement to Issue 1):49-59

Singh KP, Marak AR, Meera TH (2013) Multifactorial analysis of hanging deaths. Journal of Medical Society 27(1):49

Surís JC, Parera N, Puig C (1996) Chronic illness and emotional distress in adolescence. J Adolesc Health 19(2):153-156

Sweetman SC (2009) Martindale: the complete drug reference. Pharmaceutical Press, London

Timby J, Reed C, Zeilender S, Glauser FL (1990) "Mechanical" causes of pulmonary edema. Chest 98(4):973-979

Toro K, Pollak S (2009) Complex suicide versus complicated suicide. Forensic Sci Int 184(1-3):6-9

Verrotti A, Cicconetti A, Scorrano B, De Berardis D, Cotellessa C, Chiarelli F, Ferro FM (2008) Epilepsy and suicide: pathogenesis, risk factors and prevention. Neuropsychiatr Dis Treat 4(2):365

Ware LB, Matthay MA (2005) Acute pulmonary edema. N Engl J Med 353(26): 2788-2796

Willms D, Shure D (1988) Pulmonary edema due to upper airway obstruction in adults. Chest 94(5):1090-1092

World Health Organization, Regional Office for South-East Asia (2001) Suicide prevention: emerging from darkness - celebrate life. WHO Regional Office for South-East Asia, New Delhi http://www.who.int/iris/handle/10665/205957. Accessed 12 Feb 2017

Yaylacı S, Demir MV, Acar B, Sipahi S, Tamer A (2012) Successful treatment of excessive dose of carbamazepine. Indian J Pharmacol 44(3):417 